J. Lake Sci. (湖泊科学), 2019, 31(1): 65-71

DOI 10. 18307/2019. 0106

(C) 2019 by Journal of Lake Sciences

\title{
纳米气泡改性矿物颗粒的湖泊沉积物一水界面增氧效果实验研究"
}

\author{
余萍萍 ${ }^{1,2}$, 王敬富 ${ }^{2 * *}$, 陈敬安 ${ }^{2}$, 张 耀 ${ }^{3}$, 陈 权 $^{2,4}$, 卢耀庭 ${ }^{2,4}$ \\ ( 1 : 贵州大学资源与环境工程学院, 贵阳 550025$)$ \\ (2: 中国科学院地球化学研究所环境地球化学国家重点实验室,贵阳 550081) \\ (3: 贵州师范大学地理与环境科学学院, 贵阳 550001) \\ (4: 中国科学院大学, 北京 100049)
}

\begin{abstract}
摘 要: 季节性缺氧导致夏季沉积物内源磷强烈释放, 加剧水体富营养化, 是我国西南地区深水湖泊 (水库) 面临的重要 挑战. 有效增加夏季缺氧期深水沉积物一水界面的含氧量, 是减少内源磷释放的关键. 现有的深水增氧技术由于缺乏对沉 积物一水界面增氧的针对性, 因此治理效果有限. 近年来, 纳米气泡已被证实具有的稳定性好、氧传质速率高和环境风险 低等优点,为新型深水增氧技术研发提供了巨大潜力. 本文以天然矿物材料白云母、绢云母、硅藻土和沸石为基底,负载 纳米气泡,研发纳米气泡改性矿物颗粒技术,开展湖泊沉积物一水界面增氧模拟实验研究,运用平面光电极技术评估其界 面增氧效果. 结果表明, 纳米气泡改性矿物颗粒对沉积物一水界面具有比较明显的增氧效果. 其中,改性白云母、绢云母和 沸石的界面持续增氧时间可达 7 天以上,增氧后的界面最大溶解氧 (DO) 浓度达 $4.40 \mathrm{mg} / \mathrm{L}$, 而改性硅藻土不具有增氧能 力. 其次, 矿物粒度对改性颗粒的增氧效果有一定影响: 粒度越细,界面的最大增氧浓度越高, 且持续增氧时间越长. 纳米 气泡改性矿物颗粒技术有望成为夏季缺氧期深水沉积物一水界面精准增氧和内源污染控制的有效技术手段.
\end{abstract}

关键词: 纳米气泡; 天然矿物; 沉积物一水界面增氧; 平面光电极技术

\section{Experimental study on the oxygenation efficiency of nano-bubble modified mineral particles at the sediment-water interface in lakes}

\author{
YU Pingping ${ }^{1,2}$, WANG Jingfu ${ }^{2 * *}$, CHEN Jing' an $^{2}$, ZHANG Yao ${ }^{3}$, CHEN Quan ${ }^{2,4}$ \& LU Yaoting ${ }^{2,4}$ \\ (1: College of Resource and Environmental Engineering, Guizhou University, Guiyang 550025, P.R.China) \\ (2: State Key Laboratory of Environmental Geochemistry, Institute of Geochemistry, Chinese Academy of Sciences, Guiyang \\ 550081, P.R.China) \\ (3: College of Geography and Environmental Sciences, Guizhou Normal University, Guiyang 550001, P.R.China) \\ (4: University of Chinese Academy of Sciences, Beijing 100049, P.R.China)
}

\begin{abstract}
Seasonal hypoxia that enhancing the release of phosphorus from sediment in summer and exacerbating the water eutrophication is a big challenge for deep-water lakes ( reservoirs) in southwest China. Increasing the oxygen level of the sediment-water interface ( SWI) during summer anoxic periods is the key to reduce the internal phosphorus release. The existing deep water oxygenation technology has limited efficiency due to lacking pertinence to the SWI. In recent years, the nano-bubbles provide great potential for the development of a new oxygenation technology, which have advantages of good stability, high oxygen mass transfer rate and low environmental risk. In this study, the natural minerals, i.e., white mica, sericite, diatomite and zeolite, were modified by nano-bubbles to develop a new oxygenation technology. Simulation experiments were conducted to assess the efficiency of the newly established oxygenation technology by using planar luminescent optode technology. Our results showed that the nano-bubbles modified mineral particles obviously increased the oxygen concentrations of the SWI. The duration of continuous oxygenation for white mica, sericite and zeolite can be over 7 days, while maximum dissolved oxygen concentration at the SWI was more than $4.40 \mathrm{mg} / \mathrm{L}$.
\end{abstract}

* 贵州省重大应用基础研究计划项目（黔科合重大字［2015]2001)和贵州省科技计划项目(黔科合 [2016]支撑 2802 号) 联合资助. 2018-03-26 收稿;2018-05-16 收修改稿. 余萍萍(1994 ), 女, 硕士研究生; E-mail : 790514308@ qq.com.

** 通信作者; E-mail: wangjingfu@ vip.skleg.cn. 
The modified diatomite had no ability to increase oxygen level of the SWI. Minerals with fine grain size have the stronger oxygenation efficiency and the longer oxygenation duration. The nano-bubbles modified mineral technology provides new technical support for the precise oxygenation of SWI and effective control of sediment pollution in lakes.

Keywords: Nano-bubbles; natural minerals; oxygenation of the sediment-water interface; planar luminescent optode technology

深水湖泊是指水体中存在明显温跃层的湖泊, 其上、下层水体通常不发生大的交换 ${ }^{[-2]}$. 在深水湖泊中, 表层水体产生的藻类等有机质不断沉降至下层水体, 伴随着有机质降解等耗氧过程, 下层水体溶解氧含量 逐步下降, 从而导致深层水体长期处于缺氧状态. 深水湖泊一旦形成严重缺氧环境 ( 溶解氧浓度 $<2 \mathrm{mg} / \mathrm{L}$ ), 就可能造成“下层水体缺氧 $\rightarrow$ 沉积物磷等内源污染物释放增强 $\rightarrow$ 湖泊初级生产力提高 $\rightarrow 下$ 层水体缺氧加 剧” 的正反馈效应 ${ }^{[3-4]}$. 西南地区是我国水资源的富集区, 深水水库是该地区水资源利用的主要形式. 夏季缺 氧已成为西南深水水库沉积物一水界面的重要特征 ${ }^{[2,5]}$, 也是导致沉积物内源磷释放的关键因素 ${ }^{[6-8]}$. 因此, 研究建立有效的深水沉积物一水界面增氧技术对西南深水水库富营养化和内源污染治理具有重要科学价值 和现实意义.

深水增氧理论与技术研究始于 1940s, 至今已取得了长足发展, 目前应用较多的深水增氧技术有 4 种, 即人工去分层技术、气体提升技术、Speece 雉形技术及气泡羽流扩散技术 ${ }^{[9-10]}$. 人工去分层技术是将下层水 体提升到表面, 通过与大气接触的方式完成充氧 ${ }^{[11]}$. 气体提升增氧技术与 Speece 锥形增氧技术均是将深层 水体输送至固定的接触室中完成水体增氧, 不同之处在于接触室中的水流方向. 气泡羽流扩散增氧技术是 将气体从打满小孔的管状发射器中喷射出来形成羽流状的气水混合物, 带动下层缺氧水体缓慢上升, 到达 一定高度后富氧水体下沉并向四周扩散. 然而这些现有的深水增氧技术缺乏对沉积物一水界面增氧的针对 性,因此对沉积物一水界面的增氧效果十分有限.

纳米气泡是指直径小于 $1 \mu \mathrm{m}$ 的气泡, 普遍认为纳米气泡的形成机制是固一液界面的过剩气体分子以纳 米气泡的形式直接在固体表面聚集而成. 根据经典热力学理论计算, 纳米级气泡存在时间不超过 $1 \mathrm{~ms}$. 然 而, 大量的实际观测显示, 纳米气泡的稳定性远远超出经典理论的计算结果, 其存在时间可从数小时到数 天, 甚至数月. 纳米气泡粒径小, 上升速度慢, 传质效果好, 环境风险低, 在各个领域的应用引起人们广泛关 注 ${ }^{[12-20]}$. 应用纳米气泡处理湖泊污染水体, 可有效降低湖泊中的有机污染物, 同时, 抑制湖底戻氧菌的有机 质分解过程, 减少水体氮、磷营养盐的含量, 抑制藻类的生长 ${ }^{[21]}$. 此外, 在纳米气泡气液界面存在负电荷, 可 以与特定的污染物相互作用, 其破裂时产生的自由基和振动波可促进污染物 (如有机酚) 的去除 ${ }^{[22]}$. 纳米气 泡具有稳定性好、氧传质速率高和无生态环境风险等优点, 在深水湖泊增氧技术研发领域表现出巨大潜力. 为此, 本文以天然矿物材料作为基底, 负载纳米气泡, 建立纳米气泡改性矿物颗粒技术, 并开展湖泊沉积物一 水界面增氧模拟实验研究, 评估该技术的界面增氧效果, 旨在为深水湖泊沉积物一水界面高效增氧和沉积物 内源污染控制提供技术支撑.

\section{1 材料与方法}

\section{1 实验仪器与材料}

实验仪器: 平面光电极设备 (PreSens 公司, 德国)、便携式水质参数仪(HQ40D, HACH 公司, 美国) 、分析 天平、扫描电镜分析仪 (JSM-6460LV)、Milli-Q 超纯水机、空气葲、彼得森采泥器等.

实验材料: 白云母、绢云母、硅藻土购置于广州拓亿贸易有限公司, 沸石购置于宁波嘉和新材料科技有 限公司, 甲醇 $(>99.9 \%)$, 亚硫酸钠 $\left(\mathrm{Na}_{2} \mathrm{SO}_{3}\right)$, 有机玻璃盒 $(8 \mathrm{~cm} \times 8 \mathrm{~cm} \times 30 \mathrm{~cm})$ 等.

\section{2 矿物材料的表征}

本实验选用扫描电镜 (SEM) 对矿物表面形貌进行表征, 工作电压为 $25 \mathrm{kV}$, 在背散射模式下, 以 $10 \mathrm{~mm}$ 的工作距离对矿物材料表面进行成像.

\section{3 纳米气泡改性矿物颗粒的制备}

纳米气泡的制备方法有溶液替换法 (如醇-水替换法)、直接滴加法、电解法、温差法、基底加热法、光催 化法以及电子束、局域加热法等. 本实验选用醇-水替换法制备纳米气泡, 具体操作为: 在室温 $20^{\circ} \mathrm{C}$ 条件下, 
向甲醇 (纯度 $>99.9 \%$, 国药集团化学试剂有限公司) 中通人空气 ( $300 \mathrm{ml} / \mathrm{min}, 30 \mathrm{~min}$ ) 获得饱和甲醇溶液; 取 上述溶液置于烧杯中, 加人一定量矿物颗粒浸润; 利用 Milli-Q 超纯水替换甲醇 (醇/水比为 1:9), 由于过饱 和颗粒表面将生成一定浓度的纳米气泡 ${ }^{[23]}$.

\section{4 改性矿物颗粒的增氧效果试验}

平面光电极 (planar luminescent optode sensors,PO) 技术是基于光纤传感器的一种具有二维高分辨率的 测量技术. 该方法主要是通过物理或化学方法将苂光染料均匀地固定至平面基材表面制成传感膜,传感膜 与待测物质接触后光学性质会发生改变, 并利用相机或其他感光元件捕获传感膜与待测物质接触前后的光 学图片, 最后通过图片光学性质改变的量来反映待测物质的含量 ${ }^{[24]}$.

在贵州典型深水湖泊红枫湖羊昌河湖区 $\left(26^{\circ} 27^{\prime} 06^{\prime \prime} \mathrm{N}\right.$, $106^{\circ} 23^{\prime} 13^{\prime \prime}$ E) 用彼得森采泥器抓取表层沉积物, 装人塑料 桶混合均匀后静置培养 3 天. 事先将平面光电极氧膜裁剪 成 $1 \mathrm{~cm} \times 5 \mathrm{~cm}$ 的长条状贴于有机玻璃盒内侧, 用于观测沉 积物一水界面溶解氧 (DO) 浓度变化 (图 1). 向有机玻璃盒 填人沉积物 (高度约 $5 \mathrm{~cm}$ ), 虹吸法加人无氧水 $\left(\mathrm{C}_{\mathrm{Na}_{2} \mathrm{SO}_{3}}=\right.$ $0.002 \mathrm{~mol} / \mathrm{L}$ ), 模拟缺氧状态的沉积物一水界面. 再将经 醇-水替换的不同矿物颗粒分别投放到沉积物表面, 设置 两组空白实验. 平面光电极测量前, 用空气原向上覆水充 气, 同时用水质参数仪测量水中 DO 浓度变化, 获取 $0 、 4.40$ 和 $8.80 \mathrm{mg} / \mathrm{L}$ 时的平面光电极氧苂光变化图, 进而获得 $D O$ 校正曲线. 在模拟实验中, 将纳米气泡改性矿物颗粒投人 至沉积物表面,联合应用水质参数仪和 PO 设备对沉积物 一水界面处 DO 含量变化进行连续观测. 实验过程中模拟

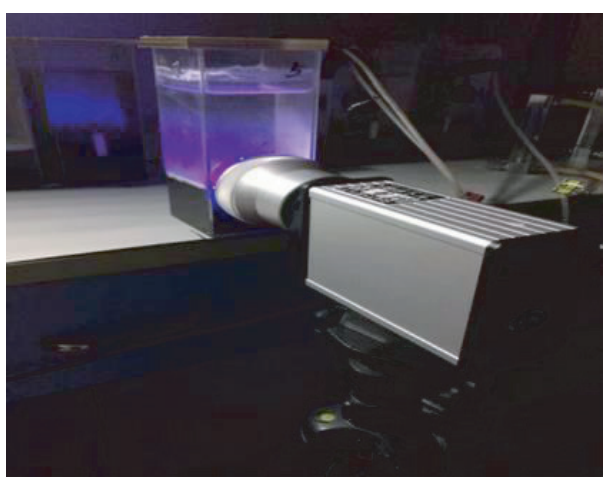

图 1 平面光电极与模拟实验装置

Fig.1 Planar luminescent optode sensors (PO) and simulation experimental device 装置始终处于黑暗条件下, 实验温度控制在 $16 \pm 1^{\circ} \mathrm{C}, \mathrm{PO}$ 每隔 $12 \mathrm{~h}$ 监测一次, 实验周期为 7 天.

\section{2 结果与讨论}

\section{1 矿物材料的表面形态表征}

在以矿物为基底制备纳米气泡的时候, 除了制备方法、温度以及气源等影响气泡生成量外, 矿物表面形 貌也是很重要的影响因素. 纳米气泡能较稳定的附着在平整的表面, 而粗粘的表面因为具有较高的比表面 积, 易于生成纳米气泡. 本研究通过扫描电镜分析仪 (SEM) 获得了所篎选的几种天然矿物材料的表面形貌 图像. 如图 2 所示, 白云母呈清晰的片状, 切面为层状结构, 沸石呈块状, 表面凹凸不平, 硅藻土呈不规则的 絮状, 绢云母部分呈片状. 通常情况下, 平整的表面有利于纳米气泡的生成和稳定.

\section{2 不同改性矿物颗粒的增氧效果对比}

黑暗条件下保持温度在 $16 \pm 1^{\circ} \mathrm{C}$, 每隔 $12 \mathrm{~h}$ 监测一次, 获取沉积物一水界面处的 PO 氧含量变化一维图 (图 3). 空白实验中 (即未投加矿物颗粒条件下), 水体中 DO 浓度仅为 $0.04 \mathrm{mg} / \mathrm{L}$ 左右, 并在整个实验周期 内基本保持不变. 5 天后略有增加 (从 $0.04 \mathrm{mg} / \mathrm{L}$ 上升至 $0.16 \mathrm{mg} / \mathrm{L}$ ), 可能因为此时水体中过量的 $\mathrm{Na}_{2} \mathrm{SO}_{3}$ 消 耗完, 空气里的氧逐渐向水体发生传质. 当向沉积物表面分别投加纳米气泡改性白云母、绢云母和沸石后, 水体 DO 浓度均有不同程度的升高, 分别使 DO 浓度最大增加到 4.40、2.00 和 $3.10 \mathrm{mg} / \mathrm{L}$, 增氧效果至少可维 持 5 天, 之后 DO 浓度出现一定程度的降低. 这主要是因为沉积物中还原性物质、微生物活动等不断耗氧造 成的. 但投加纳米气泡改性硅藻土后, 水体 DO 浓度不增反降, 说明纳米气泡改性硅藻土没有起到向水体和 沉积物增氧的效果.

纳米气泡改性白云母颗粒层和颗粒层上覆水体 DO 浓度的二维空间变化如图 4 所示. 苂光膜颜色从蓝 到白代表 DO 浓度逐渐上升, 可见载氧矿物颗粒层 DO 浓度显著高于上覆缺氧水体, 开始是 $3.90 \mathrm{mg} / \mathrm{L}$, 逐渐 向上覆水中扩散, 随时间变化最后降低为 $0.05 \mathrm{mg} / \mathrm{L}$, 而上覆水界面处 DO 浓度开始是 $0.05 \mathrm{mg} / \mathrm{L}$, 慢慢增加, 

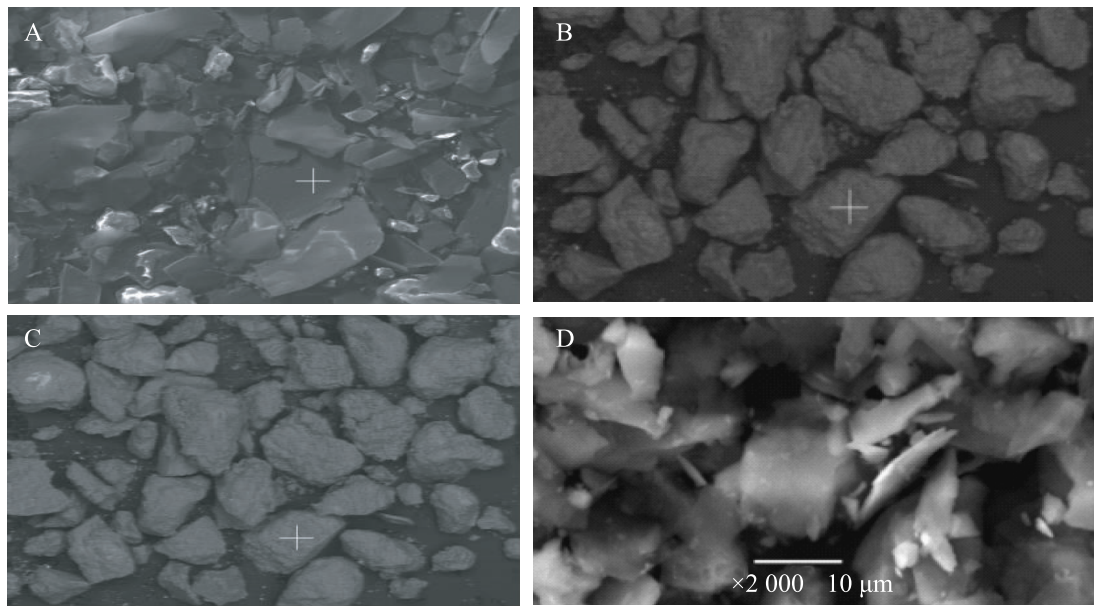

图 2 矿物颗粒 SEM 图: (A) 白云母; (B) 沸石; (C) 硅藻土; (D) 绢云母

Fig.2 SEM of mineral grains: (A) white mica; (B) zeolite; (C) diatomite; (D) sericite
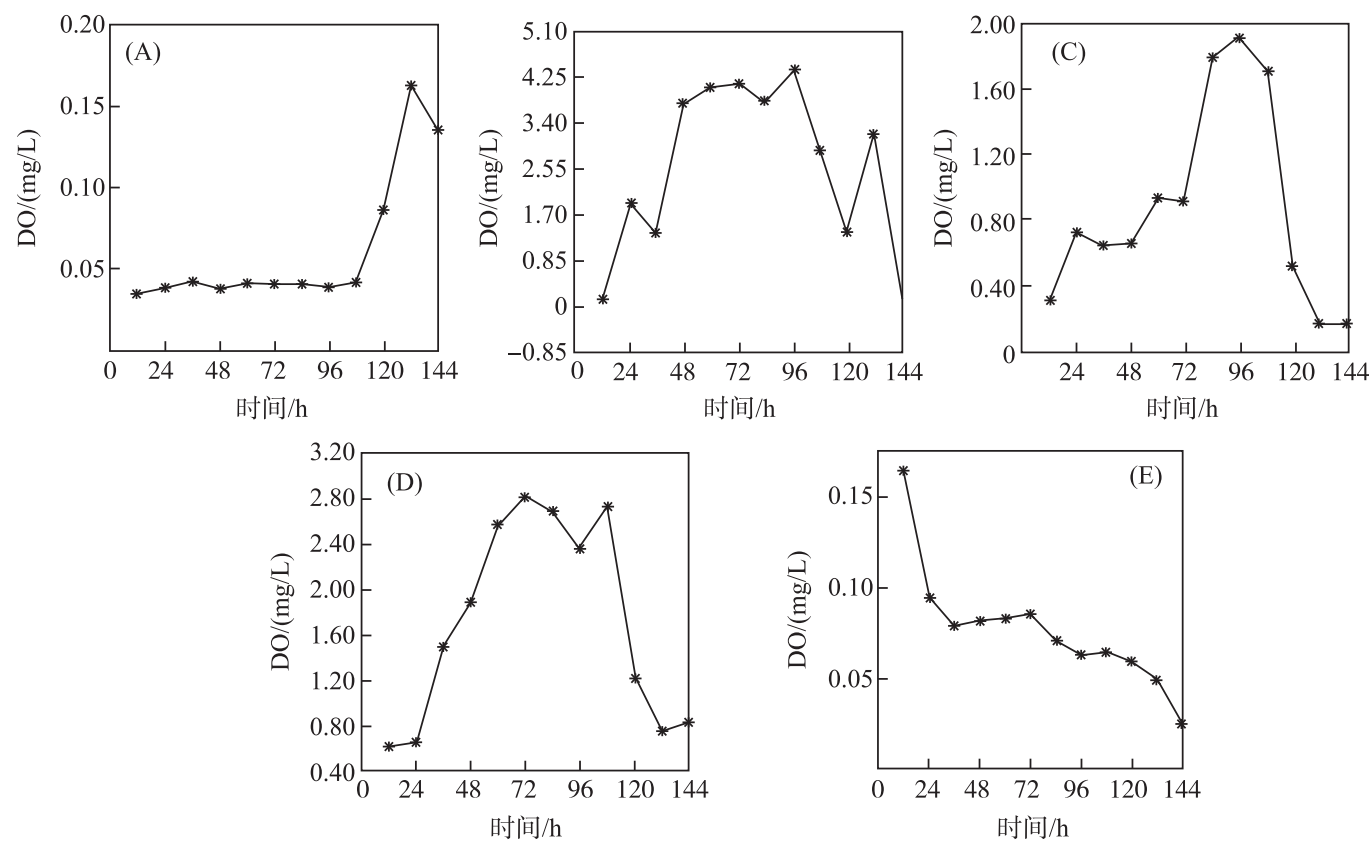

图 3 沉积物一水界面处溶解氧( DO) 浓度的时间变化:

(A) 空白; (B) 白云母; (C) 绢云母; (D) 沸石; ( E) 硅藻土

Fig.3 Temporal variation of dissolved oxygen (DO) concentrations at the sediment-water interface:

(A) blank; (B) white mica; (C) sericite; (D) zeolite; (E) diatomite

最后升至 $1.70 \mathrm{mg} / \mathrm{L}$.

利用多参数水质监测仪同步获取了沉积物一水界面 DO 浓度变化曲线 (图 5 ). 可见, 以白云母、沸石和 绢云母作为基底的改性颗粒投人缺氧水体, 可以使水体 DO 浓度分别增加 $3.50 、 3.00$ 和 $2.00 \mathrm{mg} / \mathrm{L}$, 白云母增 氧效果最为明显, 而硅藻土没有增氧效果, 这与 PO 监测结果一致. 白云母改性颗粒增氧效果较好的原因是 其具有亲水的、原子级平整的表面,能够负载纳米气泡的可能原因是在云母形成过程中存在非常小的缺陷, 

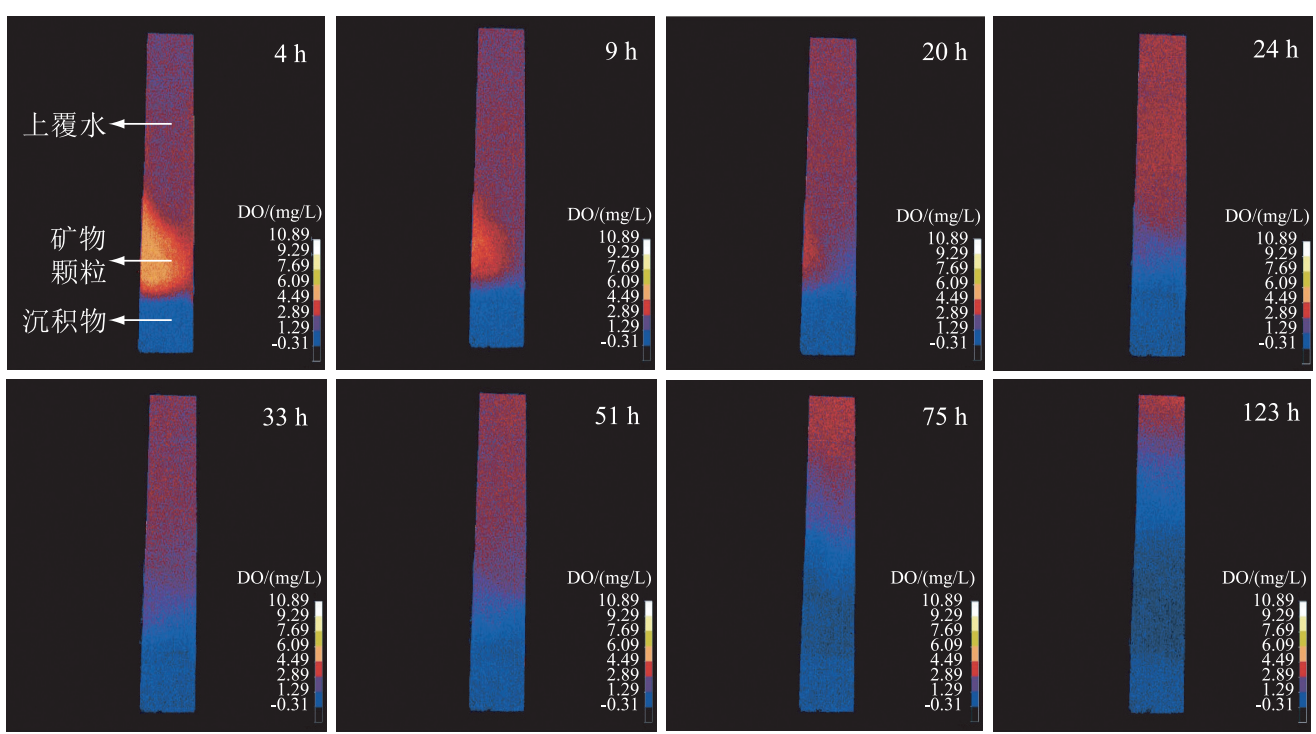

图 4 载氧白云母颗粒的增氧效果

Fig.4 Oxygenation efficiency of nano-bubble modified white mica particles

它们在纳米气泡形成过程中起到成核中心的作用而不是那些裂缝或者空穴, Davies 等的研究表明表面缺陷 是某些反应的活性中心 ${ }^{[25]}$, 且纳米气泡在平整的表面上具有较高的稳定性.

\section{3 改性矿物颗粒粒度对增氧效果的影响}

以不同粒度白云母作为基底制备纳米气泡改性颗粒, 投人沉积物一水界面后, 利用多参数水质监测仪获 取界面处 DO 浓度变化曲线 (图 6). 可见,当白云母粒度分别为 $6000 、 3000 、 1250 、 800$ 和 325 目时, 界面 DO 浓度最大分别可增加 4.66、3.59、3.44、3.29 和 $3.06 \mathrm{mg} / \mathrm{L}$. 故粒度对增氧效果也有一定影响, 颗粒越细, 增氧 效果越明显. 此结论与赵婉辰等 ${ }^{[26]}$ 的研究结果一致. 赵婉辰等 ${ }^{[26]}$ 向云芝糖肽、平消片、壳聚糖悬浮液中充氧 气制纳米气泡获得富氧制剂, 再用富氧制剂向缺氧水体增氧, 最后得出颗粒尺寸相对较小的云芝糖肽增氧 幅度最大, 尺寸小, 比表面积大, 有利于纳米气泡的吸附; 而纳米尺寸的壳聚糖富氧制剂增氧幅度最小, 是因 为壳聚糖粒度小于纳米气泡本身, 不利于纳米气泡的吸附.

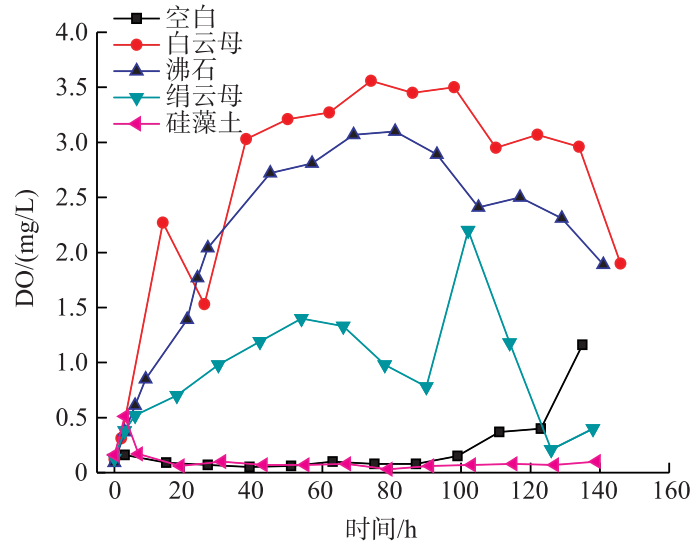

图 5 不同改性矿物颗粒的 增氧效果

Fig.5 Oxygenation efficiency of different modified mineral particles

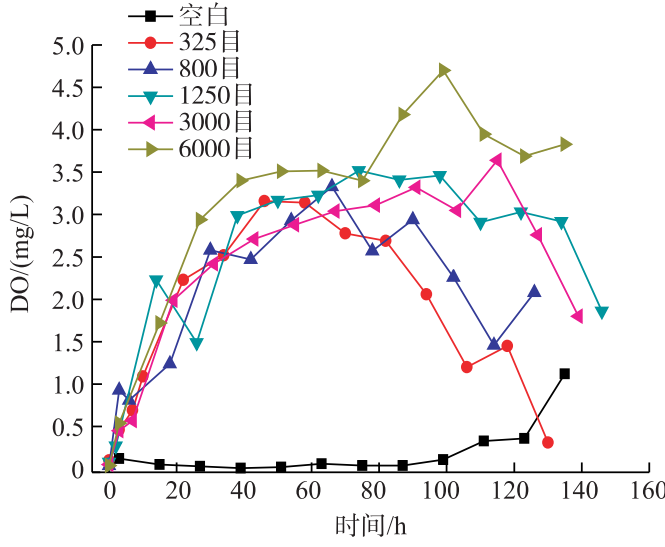

图 6 粒度对改性白云母颗粒 沉积物一水界面增氧效果的影响

Fig. 6 Effect of grain size on the oxygenation efficiency of modified white mica particles 


\section{3 结论与展望}

本研究以天然矿物为基底制备纳米气泡, 在实验室条件下研究了其对湖泊沉积物一水界面的增氧效果, 得出如下结论:

1) 在室内模拟条件下, 纳米气泡改性矿物颗粒对缺氧沉积物一水界面具有明显的增氧效果. 改性矿物 材料可对沉积物一水界面进行长时间的持续增氧 (>7 天), 界面溶解氧( DO) 浓度最高达到 $4.40 \mathrm{mg} / \mathrm{L}$.

2 ) 不同矿物的界面增氧效果差异显著. 其中, 改性矿物白云母表现出较好的增氧性能. 其次, 矿物粒度 越细,界面增氧效果越好, 持续增氧时间也越长.

3) 纳米气泡改性矿物颗粒技术具有针对性强、增氧效果好、价格低廉、环境风险低等诸多优点, 有望成 为深水缺氧湖泊沉积物一水界面精准增氧和内源污染控制的有效技术手段.

本研究证实了纳米气泡改性矿物颗粒对缺氧沉积物一水界面具有一定的增氧能力,但在增氧效率、增氧 持续时长和投放技术等方面距离实际应用仍有差距, 且该技术的生态效应和环境风险亦有待科学评估. 因 此, 在未来研究工作中将通过采用纯氧气源和矿物表面疏水改性等方法, 尝试获取高密度氧纳米气泡, 提高 该技术的增氧效率和增氧持续时长. 同时,采用高分辨采样与监测技术, 如薄膜扩散梯度 (DGT) 技术, 定量 评估载氧颗粒对湖泊沉积物一水界面磷酸盐释放通量的控制效果以及对上覆水水质和微生物群落组成的影 响,阐明纳米气泡改性矿物颗粒技术的生态效应和环境风险.

\section{4 参考文献}

[ 1 ] Elci S. Effects of thermal stratification and mixing on reservoir water quality. Limnology, 2008, 9(2) : 135-142.

[ 2 ] Chen JA, Wang JF, Yu J et al. Characteristics and prospects of reservoir ecological environment in southwest China. Earth and Environment, 2017, 45(2): 115-125. [陈敬安, 王敬富, 于佳等. 西南地区水库生态环境特征与研究展望. 地 球与环境, $2017, \mathbf{4 5}(2): 115-125$. ]

[ 3 ] Ingall ED, Jahnke RA. Influence of water-column anoxia on the elemental fractionation of carbon and phosphorus during sediment diagenesis. Marine Geology, 1997, 139: 219-229.

[ 4 ] Conley DJ, Svante B, Erik B et al. Hypoxia-related processes in the Baltic Sea. Environmental Science \& Technology, 2009, 43(10): 3412-3420.

[ 5 ] Wang YC, Zhu J, Ma M et al. The seasonal stratification of the southwest canyon reservoir and the sudden deterioration of water quality. J Lake Sci, 2005, 17(1) : 54-60. DOI: 10.18307/2005.0109. [王雨春, 朱俊, 马梅等. 西南峡谷型水 库的季节性分层与水质的突发性恶化. 湖泊科学, 2005, 17(1) : 54-60.]

[ 6 ] Fan CX, Zhang L, Bao XM et al. The migration mechanism and quantification of the source elements of the sediment-water interface in Taihu Lake: 2. The thermodynamic mechanism of phosphorus release and the source-exchange conversion. $J$ Lake Sci, 2006, 18(3) : 207-217. DOI : 10.18307/2006.0303. [范成新, 张路, 包先明等. 太湖沉积物-水界面生源 要素迁移机制及定量化: 2. 磷释放的热力学机制及源-汇转换. 湖泊科学, 2006, 18(3): 207-217.]

[ 7 ] Hupfer M, Lewandowski J. Oxygen controls the phosphorus release from lake sediments a Long-lasting Paradigm in Limnology. International Review of Hydrobiology, 2008, 93(4/5): 415-432.

[ 8 ] Wang CL, Li ZX, Li JY et al. High density gas state at water/graphite interface studied by molecular dynamics simulation. Chinese Physics B, 2008, 17(7): 2646-2654.

[ 9 ] Ashley KL, Mavinic DS, Hall KJ. Oxygenation performance of a laboratory-scale Speece Cone hypolimnetic aerator: Preliminary assessment. Canadian Journal of Civil Engineering, 2008, 35(7) : 663-675.

[10] Imboden D. Restoration of a Swiss lake by internal measures: Can models explain reality. In: FWPCA International Congress: Lakes pollution and recovery. Proceedings-preprints, 1980: 29-40.

[11] Serra T, Vidal J, Casamitjana X et al. The role of surface vertical mixing in phytoplankton distribution in a stratified reservoir. Limnology and Oceanography, 2007, 52: 620-634.

[12] Michelsen DL, Lotfi M. Oxygen microbubble injection for in situ bioremediation: possible field scenario. In: Innovative hazardous waste treatment technology series. Technomic: Lancaster PA, 1991: 131-142.

[13] Tsuge H ed. The latest technology on microbubbles and nanobubbles. Tokyo: CMC Publishing Co, Ltd, 2007. 
[14] Tsuge H ed. The latest technology on microbubbles and nanobubbles II. Tokyo: CMC Publishing Co, Ltd, 2010.

[15] Kalumuck KM, Chahine GL. The use of cavitating jets to oxidize organic compounds in water. Journal of Fluids Engineering, 2000, 122(3): 465-470.

[16] Cui Z, Chang S, Fane A. The use of gas bubblingto enhance membrane processes. Journal of Membrane Science, 2003, 221 $(1 / 2): 1-35$.

[17] Wu Z, Zhang X, Li G et al. Nanobubbles influence on BSA adsorption on mica surface. Surface and Interface Analysis, 2006, 38(6) : 990-995.

[18 ] Liu G, Wu Z, Craig VSJ. Cleaning of protein-coated surfaces using nanobubbles: an investigation usinga quartz crystal microbalance. The Journal of Physical Chemistry C, 2008, 112(43) : 16748-16753.

[19] Wu Z, Chen H, Dong Y et al. Cleaning using nanobubbles: defouling by electrochemical generation of bubbles. Journal of Colloid and Interface Science, 2008, 328(1) : 10-14.

[ 20] Li H, Hu L, Xia Z. Impact of groundwater salinity on bioremediation enhanced by micro-nano bubbles.Materials, 2013, 6 (9) : 3676-3687.

[21] Li HZ, Hu LM, Xin HB. Study on the application of micro-nanobubble technology in situ restoration of contaminated groundwater. Journal of Rock Engineering, 2015, 37(2): 115-119. [李恒震, 胡黎明, 辛鸿博. 微纳米气泡技术应用 于污染地下水原位修复研究. 岩石工程学报, 2015, 37(2): 115-119.]

[22] Li P, Takahashi M, Chiba K. Degradation of phenol by the collapse of microbubbles. Chemosphere, 2009, 75 (10): 1371-1375.

[23] Lou ST, Gao JX, Xiao XD et al. Studies of nanobubbles produced at liquid/solid interfaces. Materials Characterization, 2002, 48: 211-214.

[24] Vance DH, Czarnik AW. Real-time assay of inorganic pyrophosphatase using a high-affinity chelation-enhanced fluorescence chemosensor. Jounral of the American Chemical Society, 1994, 116(20) : 9397-3398.

[25] Davies TJ, Hyde ME, Compton RG. Nanotrench arrays reveal insight into graphite electrochemistry. Angew Chem Int Ed, 2005, 44(32) : 5121-5126.

[26] Zhao WC. Hydrophobic substances carry nano-bubbles and the ability to release gas[Dissertation]. Shanghai: Shanghai Normal University, 2013. [ 赵婉辰. 疏水物质携带纳米气泡及释放气体能力的研究 [ 学位论文]. 上海: 上海师范大 学, 2013.] 